\title{
Guidelines for Idiopathic Pulmonary Fibrosis: Everything Flows
}

\author{
Vasilios Tzilas Evangelos Bouros Argyris Tzouvelekis Demosthenes Bouros \\ First Academic Department of Pneumonology, "Sotiria" Chest Diseases Hospital, Medical School, National and \\ Kapodistrian University of Athens, Athens, Greece
}

Idiopathic pulmonary fibrosis (IPF) represents a field of constant research and breakthroughs in several areas, from pathogenesis to diagnosis and treatment [1]. This is reflected by the plethora of papers regarding IPF published during the 21st century that led to the official ATS/ ERS/JRS/ALAT evidence-based guidelines for diagnosis and management of IPF [2]. This rapid evolution is further emphasized by the fact that, in 2015 , there was a need to publish updated clinical practice guidelines regarding treatment options [3]. Indeed, a number of national societies published their own guidelines in order to keep up with the increasing flow of data $[4,5]$. Such an example is the Position Paper of the Working Group for Interstitial and Rare Lung Diseases of the Swiss Respiratory Society on diagnosis and treatment of IPF [6].

The authors have to be commented not only for their initiative but also for their methodology and willingness to decide on controversial questions. An initial list of questions was distributed to the members of the Working Group, and each question was classified as "very important," "important," "of limited interest," and as "unimportant." Questions considered by the majority as "very important" and "important" formed the basis for this consensus paper. A statement regarding each question was scored from 1 (fully disagree) to 9 (fully agree). The

\section{KARGER}

(C) 2017 S. Karger AG, Basel

E-Mail karger@karger.com

www.karger.com/res level of consensus was scored as "perfect" (all respondents agreed), "very good" (median and middle $50 \%$ of respondents were found at 1 interval or $80 \%$ of respondents were within 1 interval of the median), "good" (50\% of respondents were within 1 interval of the median or $80 \%$ of the respondents were within 2 intervals of the median), "some" ( $50 \%$ of respondents were within 2 intervals of the median or $80 \%$ of respondents were within 3 intervals of the median), and "no consensus" in the remaining cases. The study contains 24 recommendations and the overall consensus agreement was very good ("good" in 1, "very good" in 19, and "perfect" in 4 statements, respectively). In addition, due to the multiple languages used in Switzerland, the Swiss guidelines were compared to current international [2, 3], German [4], and French [5] guidelines.

There are some recommendations that are worth mentioning. The Swiss report has been differentiated from the ATS/ERS/JRS/ALAT guidelines regarding the use of bronchoalveolar lavage. Bronchoalveolar lavage is not routinely recommended by the ATS/ERS guidelines [2]. However, it can offer information that can drastically alter the diagnostic and consequently therapeutic approach. Hypersensitivity pneumonitis is a characteristic example. It represents a major feature in the differential diagnosis

Prof Demosthenes Bouros, MD, PhD, FERS, FCCP, FA

First Academic Department of Pneumonology

"Sotiria" Chest Diseases Hospital, Medical School, University of Athens

Messogion Ave. 152, GR-11527 Athens (Greece)

E-Mail dbouros@med.uoa.gr 
of IPF, even in cases presenting with a definite UIP radiology pattern. Identification of an inciting antigen is lacking in more than $30 \%$ of cases. This is eloquently captured in the study by Morell et al. [7], where an initial diagnosis of IPF was changed in 20 out of 46 patients after multidisciplinary re-evaluation. Although bronchoalveolar lavage has limitations in the diagnosis of chronic hypersensitivity pneumonitis, given the fact that it can prove helpful in the diagnosis of other diseases as well (collagen-associated ILD, fibrotic NSIP), it represents a valuable clinical tool that should be performed on an individual basis as long as the expected benefits outweigh the possible complications.

Another point of differentiation from international guidelines is related to the routine administration of antiacid treatment in IPF patients. Initial promise for this approach was based on a study of the placebo groups of 3 randomized controlled trials in IPF $[8,9]$, where antiacid administration was associated with a smaller decrease in FVC. However, in another pooled analysis from the placebo groups of the pirfenidone approval trials, antiacid treatment did not improve outcomes in patients with IPF and was potentially associated with an increased risk of infection in those with advanced disease $[9,10]$. Furthermore, from a pathogenetic standpoint, one would expect that reflux would cause an airway-centered fibrosis, a pattern that according to current guidelines is considered to be incompatible with the UIP pathology pattern [2]. Actual randomized controlled trials are eagerly needed in order to reach definitive conclusions. Until then and based on available data, it is sensible not to routinely offer antiacid therapy in IPF patients.

The use of steroids in acute exacerbations of IPF represents another area where tradition seems to prevail over available data. An international working group report concluded that there are no proven, effective therapies for acute exacerbations of IPF [11]. The use of steroids is not evidence based and is mainly driven by a "nothing to lose" approach given the dismal prognosis of these patients. However, in many cases, the triggering factor is an infection [11], and furthermore, infection cannot be definitively excluded in the majority of cases. Thus, steroids and immunosuppressive therapy in general could be detrimental [12]. Enrollment in clinical trials is strongly encouraged.

Finally, although not mentioned in the Swiss Respiratory Society position paper, another crucial point is the role of HRCT regarding the diagnosis of IPF. Based on current guidelines, patients with a possible UIP pattern should undergo surgical lung biopsy to establish the diagnosis. Clinical practice has been hampered for years by the question "is it actually honeycombing or peripheral traction bronchiolectasis?" There is mounting evidence that a possible UIP pattern (especially based on the presence of traction bronchiolectasis) has sufficient positive predictive value for an underlying UIP pathology to obviate the need for tissue confirmation in patients with the appropriate clinical setting [13, 14].

The IPF field has entered an era of intensive research with clinical impact. Official guidelines from the worldwide respiratory societies are of utmost importance. However, given the wide and rapid production of new data, it is not possible to have such statements with a frequency of 1 or 2 years. The initiative from local respiratory societies to produce their recommendations can fill this gap. It can also facilitate the adoption of guidelines locally as they have the inherent advantage of knowing better than anyone else the idiosyncrasies of their local health system.

Such local efforts can have a global impact, as any stated differences can lead to new questions and promote research. The underway new IPF diagnostic guidelines of ATS/ERS will further give new inputs on the approach to IPF, in agreement with the quote of the great philosopher Heraclitus: "Everything flows and nothing remains still."

\section{References}

1 Bouros D, Tzouvelekis A: Idiopathic pulmonary fibrosis: on the move. Lancet Respir Med 2014;2:17-19.

2 Raghu G, et al: An official ATS/ERS/JRS/ ALAT statement: idiopathic pulmonary fibrosis: evidence-based guidelines for diagnosis and management. Am J Respir Crit Care Med 2011;183:788-824.
3 Raghu G, Rochwerg B, Zhang Y, et al: An official ATS/ERS/JRS/ALAT clinical practice guideline: treatment of idiopathic pulmonary fibrosis. An update of the 2011 Clinical Practice Guideline. Am J Respir Crit Care Med 2015;192:e3-e19.

4 Behr J, Günther A, Ammenwerth W, et al: German guideline for diagnosis and management of idiopathic pulmonary fibrosis. Pneumologie 2013;67:81-111.
5 Cottin V, Crestani B, Valeyre D, et al: Diagnosis and management of idiopathic pulmonary fibrosis: French practical guidelines. Eur Respir Rev 2014;23:193-214.

6 Funke-Chambour M, Azzola A, Adler D, et al: Idiopathic pulmonary fibrosis in Switzerland: diagnosis and treatment. Respiration 2017;93: 363-378. 
7 Morell F, Villar A, Montero MÁ, et al: Chronic hypersensitivity pneumonitis in patients diagnosed with idiopathic pulmonary fibrosis: a prospective case-cohort study. Lancet Respir Med 2013;1:685-694.

8 Lee JS, Collard HR, Anstrom KJ, et al: Antiacid treatment and disease progression in idiopathic pulmonary fibrosis: an analysis of data from three randomised controlled trials. Lancet Respir Med 2013;1:369-376.

9 Kreuter M, Wuyts W, Renzoni E, et al: Antacid therapy and disease outcomes in idio- pathic pulmonary fibrosis: a pooled analysis. Lancet Respir Med 2016;4:381-389.

10 Tzouvelekis A, Bouros D: Anti-acid treatment for idiopathic pulmonary fibrosis. Lancet Respir Med 2013;1:348-349.

11 Collard HR, Ryerson CJ, Corte TJ, et al: Acute exacerbation of idiopathic pulmonary fibrosis: an International Working Group report. Am J Respir Crit Care Med 2016;194:265275.

12 Papiris SA, Kagouridis K, Kolilekas L, et al: The new idiopathic pulmonary fibrosis acute exacerbations document: one step ahead but still suspended in the air. Am J Respir Crit Care Med 2017;195:267-269.

13 Tzilas V, Bouros D: Usual interstitial pneumonia pattern in the diagnosis of idiopathic pulmonary fibrosis? Lancet Respir Med 2016; 4:770-772.

14 Tzouvelekis A, Tzilas V, Papiris S, Aidinis V, Bouros D: Diagnostic and prognostic challenges in idiopathic pulmonary fibrosis: a patient's " $Q$ and A" approach. Pulm Pharmacol Ther 2017;42:21-24. 